\title{
Achieving airtightness and weather protection of CLT buildings
}

\author{
Jens-Lüder Herms ${ }^{1, *}$ \\ ${ }^{1}$ Moll bauökologische Produkte GmbH, 68723 Schwetzingen, Germany
}

\begin{abstract}
CLT buildings - a critical view concerning airtightness and weather protection during building time. Wood constructions are gaining a bigger and bigger share in the building industry as well in bigger constructions. Mainly CLT (Cross-Laminated-Timber) elements are due to it's stability, fast building up time, easy installation and high share of prefabrication a key point for this success. In this presentation I will take a critical view on the building physical properties like diffusion resistance and airtightness. Especially according to the normal building material properties of wood like swelling and dwindling of timber. As well we will take a closer look to different glue technologies which are used on adhesive tapes to seal the CLT elements airtight. There are different technologies available in the market which offer different quality levels. Another point to solve is the temporary weather protection of timber building due to an enlarged building time. Especially when we have visible surface in the walls or in the ceiling they must be protected against rain water - there are new self sticking membranes available in the market which have proven their ability to protect ceilings against rain in a large number of realised constructions. The performance of these products will be presented in some already realised projects and we will take a closer look at the requirements and problems which have been found in these projects.
\end{abstract}

\section{Airtightness and regulation of diffusion}

Airtightness is a critical issue - Heat losses and protection against mould

Building regulations, standards and an understanding of construction-physics processes all call for airtight buildings, and there is a good reason for this: the airtightness layer helps to save energy and avoid damage to structures, and also provides good heat protection in summer.

Thermal insulation decouples the indoor climate from the outdoor climate. The temperature difference between these two climate areas tries to even itself out by means of air flow, also known as convection. This involves warm air from inside the building exiting through the structure into the exterior in wintertime. The airtightness layer prevents this air flow and thus also hinders the loss of warm air to the exterior surroundings. At the same time, it helps to ensure that mould and damage to building structures due to condensation are avoided, and also provides for a pleasant indoor climate in summertime.

\subsection{The effect of a $1 \mathrm{~mm}$ gap on energy efficiency}

Airtightness is essential for energy-efficient buildings. The Fraunhofer Institute has investigated the extent of the impact of even the smallest leaks. The Institute for Building Physics in Stuttgart has studied a $1 \mathrm{~m} \times 1 \mathrm{~m}$ thermal insulation structure with an insulation thickness of $14 \mathrm{~cm}$. With gap-free, airtight installation, the previously calculated insulation performance of $0.30 \mathrm{~W} /\left(\mathrm{m}^{2} \mathrm{~K}\right)$ was confirmed. However, if the same structure has a gap with a width of just $1 \mathrm{~mm}$, the $U$ value worsens to $1.44 \mathrm{~W} /\left(\mathrm{m}^{2} \mathrm{~K}\right)$. In other words, almost five times more heat is lost compared to the airtight structure.

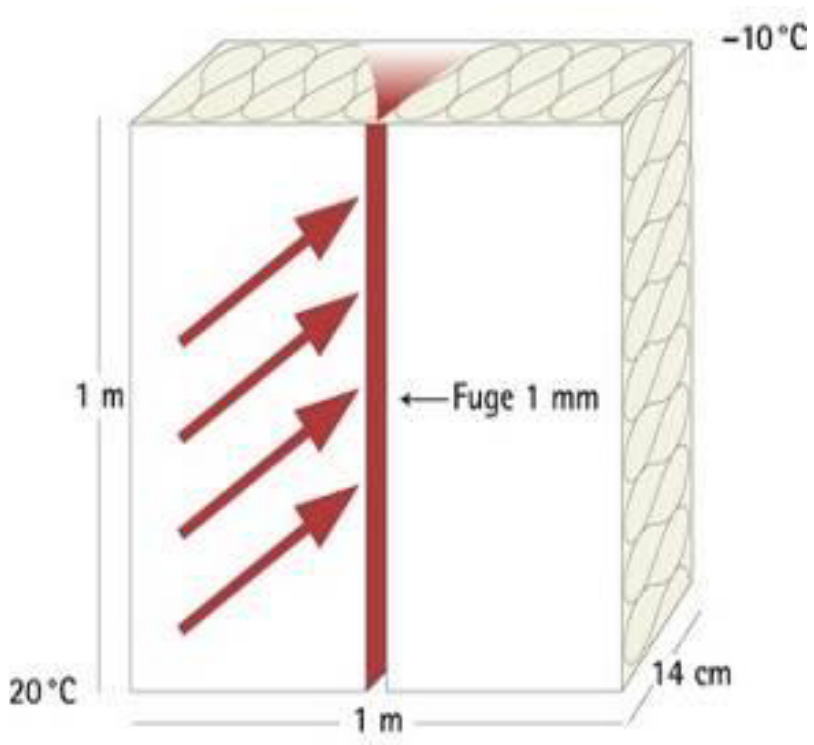

Fig. 1. Moll bauökologische Produkte GmbH $1 \mathrm{~mm}$ gap in an airtightness layer styles

\footnotetext{
* Jens Lüder Herms: jens.lueder.herms@proclima.de
} 


\subsection{Airtightness for CLT elements}

The main surface of CLT elements appears to be airtight, and this may even be true for high-quality products. However, investigations by SINTEF have shown that buildings constructed from CLT elements can only fulfil requirements if additional airtightness products are used. Significant air currents arise due to swelling and shrinkage, and also at joints between elements.

The following three possible measures are available to help achieve airtightness:

\subsubsection{With sealing products installed between CLT elements}

With this method, sealing products are pressed together by the CLT elements to such an extent that air currents through the element joints are no longer possible. Airtightness for the main surface is ensured by the elements themselves. In practice, it has been observed that these sealing products can easily be damaged during installation of the elements. This damage is difficult to rectify at a later stage.

\subsubsection{Sealing of element joints with adhesive airtightness tapes}

In this approach, all element joints are stuck with adhesive airtightness tapes, which seal the joints in an airtight manner. The elements themselves ensure the airtightness of the main surface. It is easy to visually monitor the quality of installation here, and subsequent repair of any defects is also uncomplicated.

\subsubsection{Installation of a defined airtightness layer in the form of an airtightness membrane}

In this case, an additional airtightness layer is included in plans and this is fitted to the CLT elements. This is the highest-quality solution that offers the best sealing, but it also involves increased requirements for materials and labour. An additional advantage here is that the elements themselves do not need to be airtight.

\section{Protection of elements during the construction phase}

CLT ceiling elements can be produced with an aesthetically high-standard finish. Visible ceilings are becoming increasingly popular. However, these ceilings are unprotected during the construction phase, and these elements can become damp due to rainwater.

Once the elements have dried out, ugly stains may remain that are expensive and labour-intensive to rectify

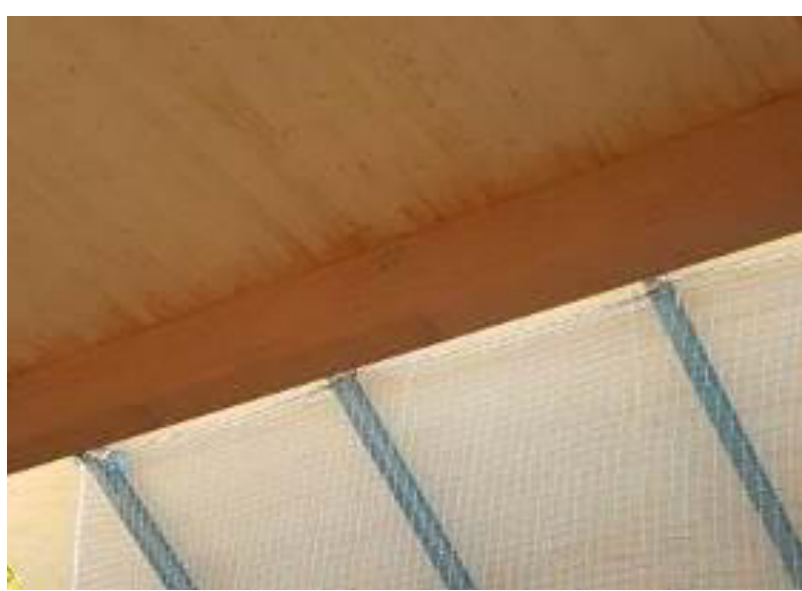

Fig. 2. Roman Szypura - Water stains on a CLT ceiling element.

\subsection{Three possible approaches for weather protection}

As a consequence, additional protection for the building is essential during the construction phase if visible elements are being used. Indeed, this protection is recommended for all other CLT buildings too. There are three approaches for providing this protection:

\subsubsection{Enclosing the entire building}

If the building site is completely enclosed, work can proceed regardless of the weather conditions. This leads to optimal working conditions for building technicians. The disadvantages are the high costs and the additional time necessary to erect and then dismantle the enclosure and the associated foundations.

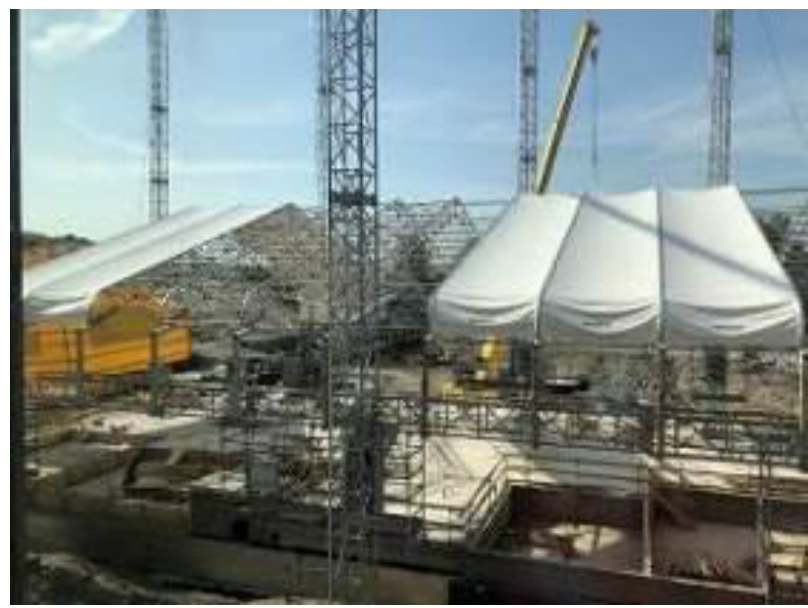

Fig. 3. Jens-Lüder Herms - Tent structure to enclose a multistorey CLT building 


\subsubsection{Covering the ceiling elements with tarpaulins}

In this case, the ceilings are covered with suitable tarpaulins. This approach is relatively inexpensive. The disadvantage of this approach is that seepage can occur behind this sheeting and even small holes may allow water to enter and spread out on the elements. In addition, folds in the sheeting can present an increased accident hazard.

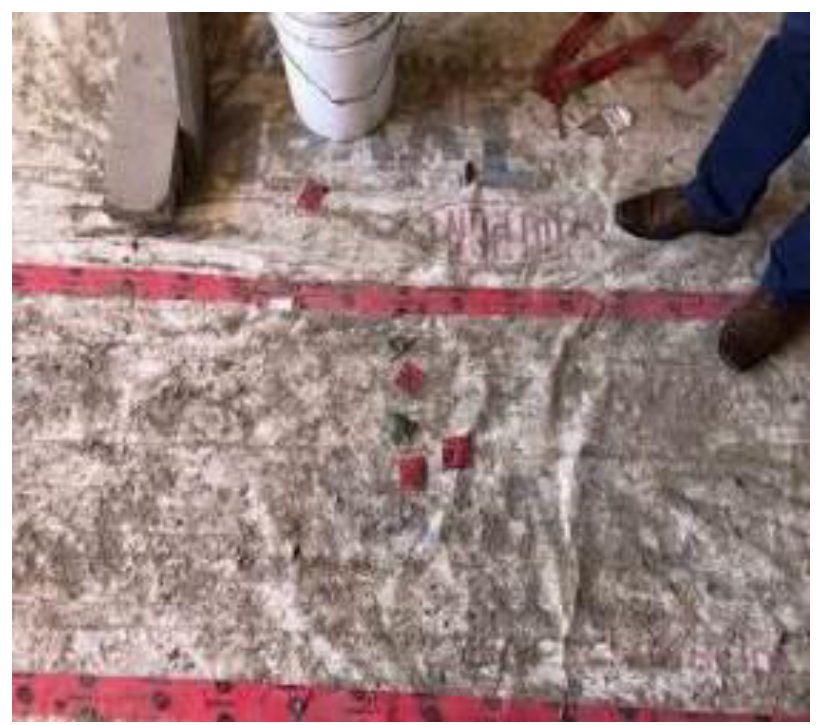

Fig. 4. Jens-Lüder Herms - Sheeting to cover a CLT ceiling elements

\subsubsection{Sealing of ceilings elements with self adhesive membranes}

In this variant, the entire ceiling element is sealed using a membrane. No seepage can occur behind this membrane, which means that the overall system does not fail even if there are isolated holes. In addition, the supports that are required can be screwed through the membrane directly without the need for any additional measures.

Full-surface adhesion means that there are no folds that would present tripping hazards. The fleece structure of the membrane also ensures that persons can safely walk across the building components. As water can no longer run off, it must be drained off in a controlled manner and run-offs must be planned.

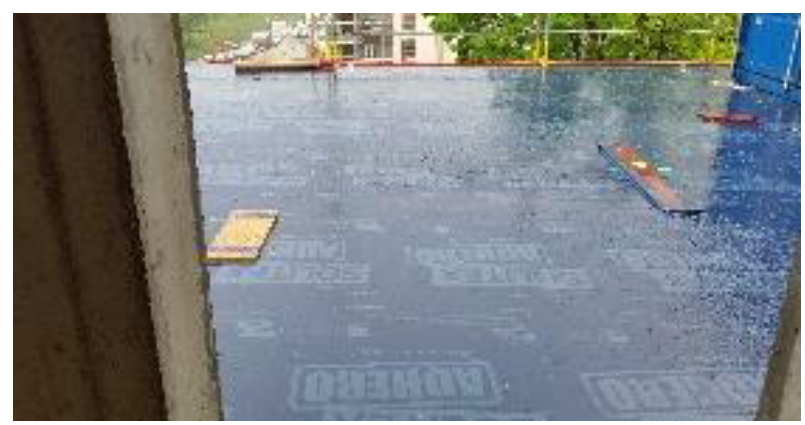

Fig. 5. Jens-Lüder Herms - Sheeting to cover a CLT ceiling elements 